\title{
COVID-19 Case Fatality Rate and Detection Ability in Indonesia
}

\author{
Tiopan Sipahutar ${ }^{1 *}$,Tris Eryando ${ }^{2}$
}

1Doctoral Program in Public Health, Faculty of Public Health, Universitas Indonesia, Indonesia

2Department of Health Informatic and Biostatistic, Faculty of Public Health, Universitas Indonesia, Indonesia

\begin{abstract}
The world is currently experiencing a COVID-19 pandemic. More than 5 million people have been infected with COVID-19 and more than 300 thousand have died from this virus worldwide. In Indonesia, the number of infected people has reached more than twenty thousand people and more than one thousand people have died from this virus. During the COVID-19 pandemic, Case Fatality Rate (CFR) was a very important measure for many people because death is very important to each person, including questions of when and how death will occur and whether there is any way to delay it. However, caution is needed in calculating and displaying CFR. This paper will present the uses and the weaknesses of CFR in the context of the COVID-19 pandemic in Indonesia.
\end{abstract}

Keywords: case fatality rate, COVID-19 pandemic, Indonesia

\section{Introduction}

Some cases of pneumonia of unknown etiology detected in Wuhan City, Hubei Province of China in the end of 2019. A total of 44 patients reported with pneumonia of unknown cause in January 2020 that have been reported to World Health Organization (WHO) by the national authorities in China. ${ }^{1}$ The consensus statement then established that the pneumonia of unknown etiology is coronavirus disease 2019 (COVID-19). ${ }^{2}$ As of March 2020, COVID-19 cases have been found globally (spread out of China), ${ }^{3}$ that Centers for Disease Control and Prevention (CDC) then recognized that the COVID19 is person-to-person spread. ${ }^{4,5}$ In March 11, 2020, based on the current situation that the COVID-19 have affected countries outside China tripled and the number of cases has increased 13-fold outside China, then WHO identified COVID-19 as pandemic. 6

The COVID-19 pandemic has drained a lot of energy, whether in physical, mental, social and economic terms. ${ }^{7}$ The calculations have continuously been made to determine the latest situation of cases that have occurred. Indeed, it has truly felt that we are living in "one world" in which no place or country is free from "contamination" of a problem that has afflicted certain regions.

The Case Fatality Rate (CFR) has especially become an intriguing subject of discussion for many people.
People cannot avoid of talking the number of death when they discuss COVID-19. In a way, this moment has presented a new opportunity for the Indonesian community to improve their knowledge on mortality measures. As previously, the CFR was known only to those in the health sector, but now more people are becoming familiar with the measure. The CFR is a measure of mortality that is feared by human being for several reasons such as because death is the ultimate experience that all human being will surrender. Moreover, death is highly importance to each person including questions of when and how death will occur and whether there is any way to delay it. $8-10$

On social media, people have been debating the national CFR and even compared it with CFR of other countries such as China and Vietnam, which have now had lower CFR compared to other country. This comparison is then followed by comparing the performance of the Indonesian government in handling pandemics under the pretext why CFR in Indonesia is higher compared to other countries. Another thing that also happens is the lots of people displaying CFR numbers in Indonesia on television or social media which then does not only make people understand but has the potential to create excessive fear or anxiety. This is a mistake because the community is more fixated on its CFR number 
compared to other information behind the CFR. Therefore, it is very important to provide understanding to the public or community regarding what is meant by the CFR and what are its weaknesses.

\section{Method}

This is a literature review study. Authors submit that it needs many considerations to interpret the CFR; and for that authors present many expert's views on how the CFR is calculated and its impact on the community.

\section{Discussion}

The Case Fatality Rate (CFR) is a common measure of the short-term severity of an acute disease; it could be used to measure any benefit of a new therapy or the effectiveness of an intervention. The CFR is defined as the proportion of cases with certain diseases or conditions that die within a certain time. Generally, the CFR is presented as a percentage. ${ }^{8-10}$ It is the proportion of people with a given disease or condition who die from it in a given period. In this pandemic context, the CFR is calculated by dividing the number of COVID-19 patients who died with the total number of patients with confirmed as COVID-19 infection. The number of COVID-19 patients who died is referred to as a numerator while the total number of COVID-19 infected patients is referred to as the denominator. ${ }^{8-10}$ In calculating CFR, it should use official data that has been confirmed by the party that issued the data. In Indonesia, official data is released by the Ministry of Health which is published daily both directly and on the official website. ${ }^{11}$

To April 27, 2020, the CFR in Indonesia was around $8.4 \% .{ }^{11}$ This figure was relatively high when compared to other countries such as Singapore, Malaysia or even China. However, people must be careful in interpreting and comparing the CFR in Indonesia with other countries. Let alone with other country, the CFR comparisons between provinces in Indonesia also vary. This difference is very reasonable, given the different characteristics of the regions in Indonesia. ${ }^{12-18}$

The calculation of CFR is particularly sensitive to the denominator: the greater the denominator, the smaller the CFR. The daily CFR figures can change according to the denominator, which in this case is the number of people who have been confirmed as positive COVID-19 based on real-time polymerase chain reaction (PCR) method. Several factors certainly affect the CFR figures every day. As we understand, COVID-19 is a new virus that is still being researched. Much information regarding the virus is still unknown. The capacity of health services; the availability of health workers, personal protective equipment, examination tools for diagnosis; and the readiness of the central and local governments are several factors that also affect the CFR. ${ }^{14,15}$

One of the factors influencing the soaring figures of the CFR is the limited number of laboratories that can be used as referral sites for conducting real-time PCR test all over Indonesia. Initially, Indonesia only used one laboratory to conduct the real-time PCR, and this assuredly yielded a slow diagnosis, which, in effect, generated very little information (Figure 1). In March 16, 2020, it was announced that 12 laboratory networks were added, then other additional 36 laboratories on April 3, and on April 29 it was declared that the total number of laboratories ready for PCR test was 89 . This addition of laboratories, however, did not necessarily lead to the increase in the

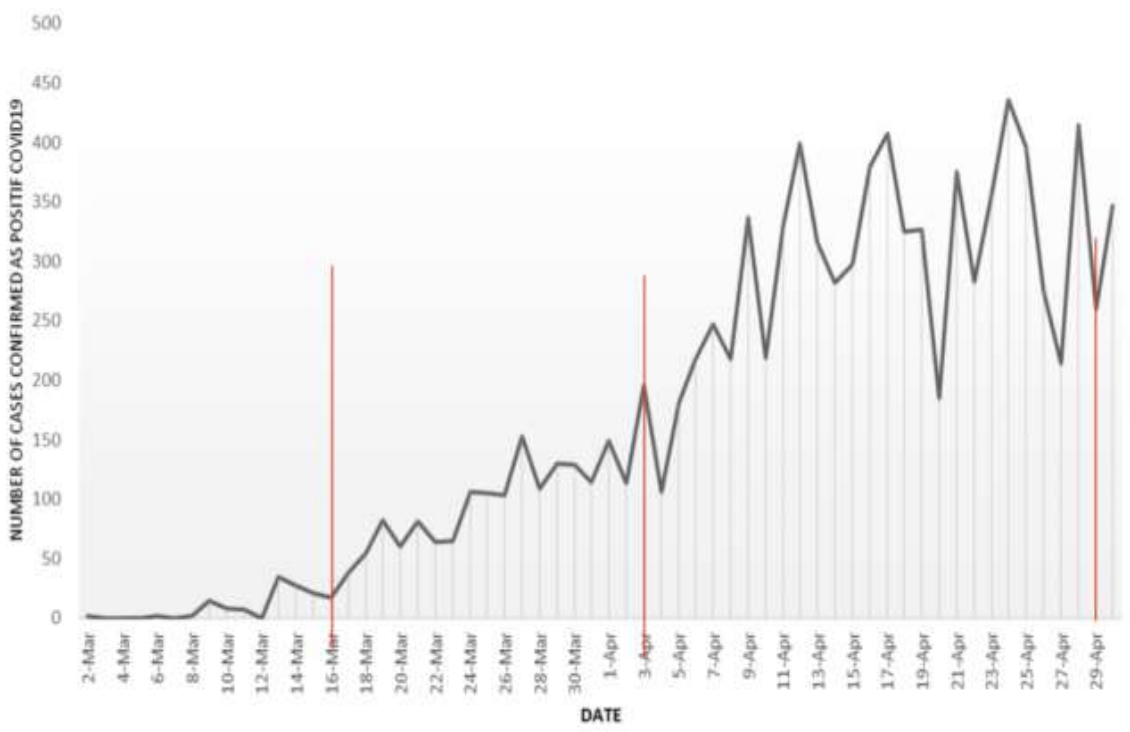

Source: https://covid19.go.id/peta-sebaran

Figure 1. The Trend of Number of Cases Confirmed Along with the Addition of Laboratory in Indonesia 
number of test because Indonesia was constrained by the limited availability of reagents and experts who were able to carry out the test. ${ }^{11,19-21}$

With the addition of laboratories and the difficulties encountered in the field, and when it compared to the vastness of Indonesia which consists of 514 districts, the overall picture, of course, is still unfavourable. Such circumstances have automatically slowed down the process of confirmation on people's status - whether or not they are infected; so the denominator would be small. In this case, the CFR tends to be over-estimated. We also understand that there were instances where patients under surveillance died but their results of real-time PCR test were not yet known. If it was later discovered that the realtime PCR test results were confirmed to be positive, then the CFR calculation in the previous time was underestimated because it had not included the numerator. $13,15,16$

Both of such conditions, underestimation, and overestimation of the CFR, have their respective impacts. Overestimation of the figures may induce fear and panic while underestimating it may lead to the lack of seriousness in the community in preventing and overcoming the spread of the COVID-19. Thus, in presenting, interpreting and comparing the CFR for the public, caution and understanding of situations or contexts are indispensable. ${ }^{14}$

Responding to this situation, we must apply the national standardization system in the context of laboratories for the equal distribution of the availability and quality of examinations or diagnoses, so when one day Indonesian is struck by a similar incident, we would no longer hear a statement that "the data from Laboratory A is unreliable" or "unconfirmed". The minimum standard must be prepared for each province, and if possible, be extended to the district or city level. ${ }^{7,11}$

Another thing of concern is the effort for modelling the COVID-19 incident, which has been confusing to the public. Every academic and research institution has conducted modelling and each modelling has been developed with an assumption. Different models were from different assumptions, and this is not even easily understood by many people. Determining when transmission occurs also need to be assumed if the model is to be calculated properly. The determination of the initial transmission can be traced back from the first positive cases reported, where these cases are continuously traced until it becomes possible to seize cases that have not been previously diagnosed - but because of a proper symptom recording - could show symptoms identical to the initially diagnosed cases. Hence, we would be able to establish a diagnosis by running this method properly until the first transmission is assuredly discovered. Another option is to simply stop at the first confirmed case and pay attention to the average transmission, hence an initial case can be determined and a model with various assumptions be built. The ability to trace back, known as disease epidemiological research, is also important to be carried out by the health department in each district or city to assist in the discovery of new cases as well as to detect the source of morbidity, which can help in handling a case of illness. $22-25$

\section{Conclusion}

Finally, this pandemic has inevitably demanded people to understand the measures used in public health problems. However, displaying the size of public health problems without further explanation may cause information bias in the community, which can potentially create adverse interpretations and conclusions. Therefore, health information, especially about the size of public health problems, need to be displayed with explanations of strengths and weaknesses. This is an opportunity to provide more education to the public considering that $50 \%$ of Indonesia's population has been connected to the internet and almost all Indonesians can access television. Thus, this difficult pandemic would not just pass by but also provide a learning effect for all Indonesians.

\section{Abbreviations \\ CFR: Case Fatality Rate; WHO: World Health Organization; COVID- 19: Coronavirus Diseases 2019; CDC: Centers for Disease Control and Prevention; PCR: Polymerase Chain Reaction.}

\section{Ethics Approval and Consent to Participate}

The study was based on data available in public domain; therefore, no ethical issue is involved.

\section{Competing Interest}

The author(s) stated that no potential conflicts of interest with respect to the research, authorship, and/or publication of this article.

\section{Availability of Data and Materials}

All material is publicly available in respective journals. The links are available in the reference list. All sources can be downloaded for free.

\section{Authors' Contribution}

All authors have made substantial contribution to this research and have approved the final manuscript.

\section{Acknowledgment}

Not Applicable

\section{References}

1. World Health Organization. Emergencies preparedness, response: pneumonia of unknown cause - China; 20 May 2020.

2. Gorbalenya AE, Baker SC, Baric RS, et al. The species severe acute respiratory syndrome-related coronavirus: classifying 2019-nCoV and naming it SARS-CoV-2. Nature Microbiology. 2020; 5: 536-44. 
3. Jogalekar MP, Veerabathini A, Gangadaran P. Novel 2019 coronavirus: genome structure, clinical trials, and outstanding questions. Experimental Biology and Medicine (Maywood). 2020; 245 (11): 9649.

4. Centers for Disease and Control and Prevention. CDC confirms person-to-person spread of new coronavirus in the United States; January 30, 2020.

5. World Health Organization. Modes of transmission of virus causing COVID-19: implications for IPC precaution recommendations; 2020.

6. World Health Organization. WHO Director-General's opening remarks at the media briefing on COVID-19 - 11 March 2020; 2020.

7. Djalante R, Lassa J, Setiamarga D, Sudjatma A, Indrawan M, Haryanto B, et al. Review and analysis of current responses to COVID-19 in Indonesia: period of January to March 2020. Progress in Disaster Science. 2020; 6: 100091.

8. Gordis L. Epidemiology. 5th Edition. Elsevier Saunders.

9. Webb P, Brain C. Essential epidemiology: an introduction for students and health professionals. 2nd Edition. Cambridge, UK: Cambridge University Press; 2011.

10. Bonita, Beaglehole, Kjellstrom. Basic epidemiology. 2nd Edition. Geneva: World Health Organization; 2006.

11. Kementerian Kesehatan Republik Indonesia. Peta sebaran COVID-19. www.covid19.go.id; 2020.

12. Onder G, Rezza G, Brusaferro S. Case fatality rate and characteristics of patients dying in relation to COVID-19 in Italy. JAMA. 2020; 323 (18): 1775-6.

13. Spychalski P, Błażyńska-Spychalska A, Kobiela J. Estimating case fatality rates of COVID-19. Lancet Infectious Disease. 2020; 20 (7):774-5.

14. Kim DD, Goel A. Estimating case fatality rates of COVID-19. Lancet
Infectious Disease. 2020; 20 (7): 773-4.

15. Rajgor DD, Lee MH, Archuleta S, et al. The many estimates of the COVID-19 case fatality rate. Lancet Infectious Disease 2020; 20 (7): 776-7.

16. Baud D, Qi X, Nielsen-Saines K, et al. Real estimates of mortality following COVID-19 infection. Lancet Infectious Disease. 2020; 20 (7): 773.

17. Xu S, Li Y. Beware of the second wave of COVID-19. Lancet. 2020; 395 (10233): 1321-2.

18. Santesmasses D, Castro JP, Zenin AA, Shindyapina AV, Gerashchenko MV, Bohang Z, et al. COVID-19 is an emergent disease of aging. medRxiv. Posted April 15, 2020.

19. Kementerian Kesehatan Republik Indonesia. Pedoman pencegahan dan pengendalian coronavirus disease (COVID-19); July 2020: pp. 1115.

20. Maharani T. Pemerintah tetapkan 12 jejaring laboratorium pemeriksaan Covid-19. kompas.com; March 16, 2020.

21. CNN Indonesia. Kemenkes: tes PCR corona massal terkendala alat dan SDM; April 22, 2020.

22. Gleick PH. No COVID-19 models are perfect, but some are useful. Time; May 19, 2020.

23. Brookmeyer R. Op-Ed: predictions about where the coronavirus pandemic is going vary widely. Can models be trusted? Los Angeles Time; April 22, 2020.

24. Jewell NP, Lewnard JA, Jewell BL. Predictive mathematical models of the COVID-19 pandemic: underlying principles and value of projections. JAMA. 2020; 323 (19): 1893-4.

25. Wynants L, Calster BV, Collins GS, Riley RD, Heinze G, Schuit E, et al. Prediction models for diagnosis and prognosis of covid-19: systematic review and critical appraisal. BMJ. 2020; 369: m1328. 